\title{
Evaluation of Pain and Tenderness in Endodontic Treatment of Deciduous Teeth using (LSTR) 3-Mix MP therapy
}

\author{
Ali M ${ }^{1}$, Moral A A ${ }^{2}$, Quader S M A³
}

Received: 13.08.2017

Accepted: 12.10.2017

Abstract:

Aim and objective: The purpose of this study was to evaluate the prognosis of pain and tenderness in endodontic treatment of deciduous teeth using LSTR 3-MixMP therapy.

Materials and method: The treatment was performed on selected 60 patients of 60 teeth which were divided into two groups; Group- $A(n=30)$ and Group- $B(n=30)$.In group-A patients were diagnosed initial pulpitis or reversible pulpitis (vital inflamed pulp) and in group-B patients were diagnosed as non-vital necrosed pulp with or without inter-radicular lesion. In both groups carious lesion and previous restorative materials were removed and the cavity was prepared in such a way which was termed as "Medication cavity". The cavity was cleaned and dried and then LSTR 3Mix MP therapy was placed at the orifice of root canals or on the bottom of the pulp chamber and then sealed with glass-ionomer cement and further reinforced with composite resin. Resolution of clinical signs and symptoms; pain and tenderness to percussion were evaluated at one week, one month, six months and one year interval.

Result: In all cases clinical symptoms such as pain and tenderness to percussion disappeared after treatment in both groups but group B showed better clinical success. Finally all the cases were evaluated as successful.

Conclusion: Based on the present study it can be concluded that endodontically involved deciduous teeth in both vital (inflamed) and non-vital teeth associated with pain and tenderness were treated successfully by LSTR 3-Mix MP therapy.

Key Words: Endodontic treatment: Deciduous tooth, 3-Mix MP therapy.

1. Dr, Mohammad Ali, Assistant Professor, (Dentistry), Bangladesh Institute of Child Health (BICH), Dhaka Shishu (Children) Hospital, Dhaka.

2. Prof. Dr. Ali Asgor Moral, Chairman- Conservative Dentistry and Endodontics \& Treasurer, Banghubandhu Sheikh Mujib Medical University, Dhaka.

3. Dr. S M Abdul Quader, Associate professor, Conservative dentistry and Endodontics \& Vice Principle, Update Dental College, Dhaka.

Correspondence : Dr. Mohammad Ali, Assistant Professor, Bangladesh Institute of Child Health (BICH), Dhaka Shishu (Children) Hospital, Dhaka.

Email: ali.mohammad3500@gmail.com,Cell:01819271054 


\section{Introduction}

Endodontically involved deciduous teeth due to carious lesion are associated with numerous bacteria. Bacteria present in Carious lesions, together with reactive inflammatory and immunological host responses, lead to the clinical development of pulpitis, pulp necrosis, periapical infections, abscess. The combination of inflammation and infections causes significant pain.

Pediatric dentists are often faced with the management of primary teeth that show signs of irreversible pulpitis or necrosis.1Traditionally accepted treatment options for teeth with infected root canals/periradicular tissue are pulpectomy or extraction ${ }^{1}$. Although extraction with space maintenance remain a viable treatment option, a successfully restored primary tooth is a superior space maintainer than an appliance $^{2-3}$.

With pulpectomy treatment necrotic or abscessed primary teeth have acceptable outcomes approximately 85 percent of the time ${ }^{4}$, but the technique can be very challenging given the continuous changes in the apical foramen as a result of physiologic and pathologic resorption. Over instrumentation may injure the developing permanent tooth bud ${ }^{4-6}$. Sjogren et al. found that, even after thorough mechanical and chemical cleaning of the canals, up to 40 percent of the canals may still exhibit positive bacterial cultures ${ }^{7}$.

These findings led researchers to investigate antibiotic option for disinfecting root canal systems. As a result, the cariology research unit of the school of dentistry, Nigata University, Japan developed the concept of lesion sterilization and tissue repair (LSTR) therapy, which is a noninstrumentation endodontic treatment that employs a mixture of antibacterial drugs in a propylene glycol vehicle for the disinfection of dentinal, pulpal and periapical lesions. If lesions are completely disinfected tissue repair can be expected ${ }^{8}$.

Further affected dentine that is clinically softened upon probing could be recalcified after disinfection ${ }^{9}$ and so, affected dentin could be intentionally left in a carious lesion. In addition, when 3-Mix (ciprofloxacin, metronidazole and minocycline) was mixed with macrogol $(\mathrm{M})$ and propylene glycol $(\mathrm{P})$ the combination has been demonstrated to penetrate efficiently dentinal lesions, via dentinal tubules, ${ }^{10}$ suggesting that bacteria in pulpal lesions could be killed by placement of 3-Mix MP at the bottom of a carious lesion. Thus one important prediction of the LSTR hypothesis is that local delivery of effective antibiotics in an appropriate vehicle to a carious lesion may lead to healing of cases of pulpal lesion without a need for conventional pulpectomy procedure. The aim of this study was to evaluate the prognosis of pain and tenderness observed in endodontically involved like reversible pulpitis (vital inflamed pulp) and non-vital necrotic pulp with or without periapical lesion in deciduous teeth using (LSTR) 3-Mix MP therapy.

\section{Methodology}

\section{Materials and Methods:}

A total of 60 children aged between 4-8 years old who were having 60 infected or inflamed primary molars teeth were selected from the out patient department of conservative dentistry and Endodontics in Bangabandhu Shekh Mujib Medical University and Pedodontics Department of Dhaka Shishu (Children) Hospital. A general examination of the children was done prior to beginning of the study, the children who were free of any contraindication of endodontic treatment were included in the study. An informed written consent was taken from patient's parents prior to start the study.

The teeth were selected by taking history, clinical and radiographic examination. Mild to moderate pain was assessed by VAS (visual analogue system) and tenderness to percussion was performed by gentle tapping with blunt handle of mouth mirror on all surface of adjacent teeth first then to the offending tooth. Tenderness was assessed as mild, moderate. Vitality and sensitivity test were done by hot and cold stimuli and electric pulp tester.

Teeth with perforated pulpal floor, radiographical evidence of excessive root resorption, deciduous molar which are near to normal shedding, nonrestorable teeth were excluded from the study.

The entire number of respondents was divided into two groups according to diagnosis of the patients.

Group-A: Vital inflamed pulp( initial pulpitis or reversible pulpitis)

Group-B: Non-vital necrotic pulp( with or without periapical lesion).

\section{Preparation of 3-Mix Mp therapy}

Commercially available three antibacterial drugs as ciprofloxacin, metronidazole and Minocycline were used in this study. After removal of the enteric coating and the capsules that enclose the drug products, each of the drugs were pulverized and kept separately- in tightly capped porcelain containers to prevent exposure to the light and moisture. These drugs were 
stored in refrigerator. Care was taken not to open the containers before they had reached room temperature when used. Before start the treatment the powdered drugs were taken in the ratio of 1:1:1 ciprofloxacin, metronidazol, minocycline and were mixed thoroughly which called. 3-Mix and was kept. One part of macrogol (M) and one part of propylene glycol (P) was taken and then mixed well to make up MP.

One part of MP against 7 parts of 3-Mix (powder) is needed to make 3 mix-MP. These 3 Mix MP were mixed properly and final preparation was small ball like structure of $1 \mathrm{~mm}$ of diameter (Fig-2).

\section{Clinical procedure of LSTR}

Clinical symptoms such as pain, tenderness to percussion were recorded prior to treatment start.

Access cavity was performed, carious lesions and any restoration if present was removed with bur but in group-A care was taken not to cleaned pulpal floor with bur to avoid pulp exposure.Pulpal floor was cleaned with excavator if any soften dentin present. The cavity was prepared such a way to creat a medication cavity. [Fig-3].

The cavity was cleaned with sodium hypochoride and normal saline and dried, then 3-Mix MP therapy was placed at the orifice of root canal in group-B and on the bottom of the pulp chamber in group-A and sealed by glassionomer ( Fuji-IX) and finally reinforced by composite resin [Fig-4]. The whole procedure was completed in one visit.

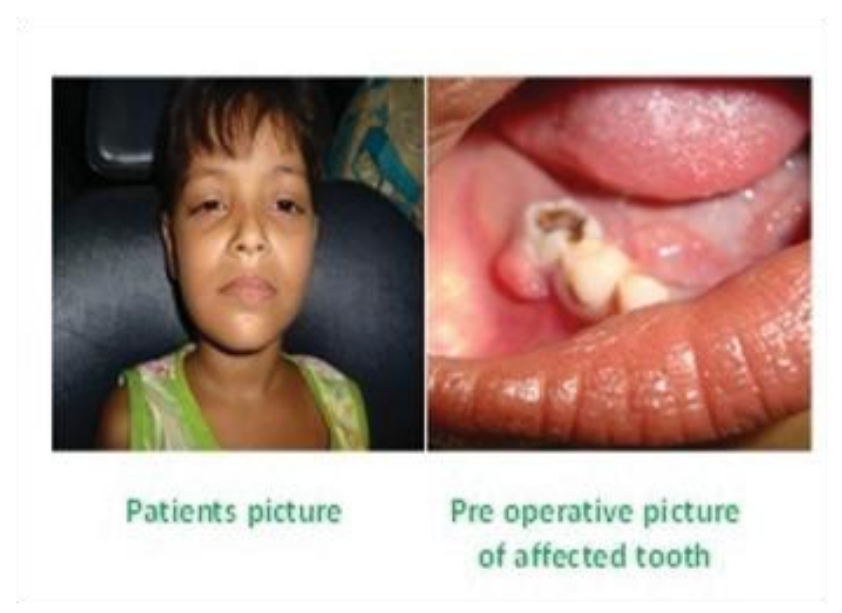

Figure 1

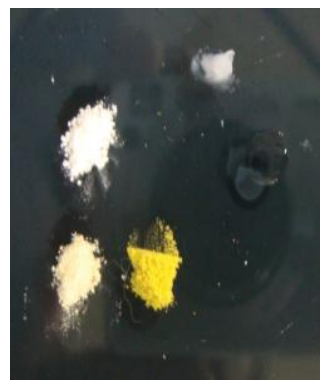

3Antibiotics, propylene glycol \& macrogol

Figure 2

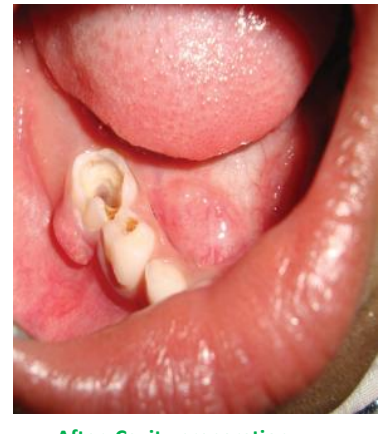

After Cavity preparation

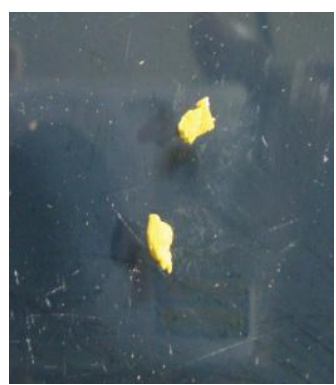

3 MIX MP

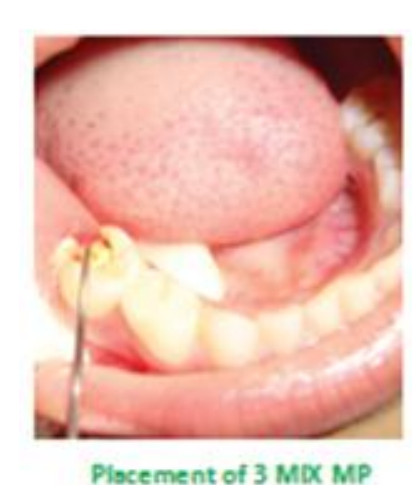

Figure 3

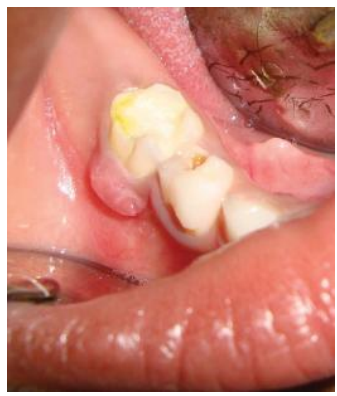

After treatment

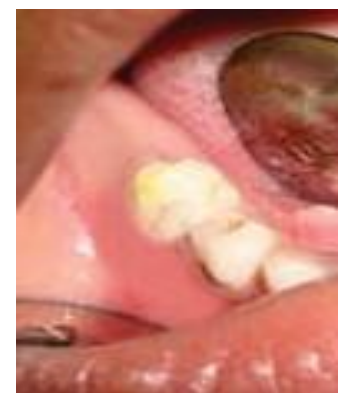

After 1 month follow-up
Figure 4

\section{Evaluation of pain and tenderness to percussion} The tooth was considered success depending upon clinical evaluation. Each patient was examined intraoperatively and post operatively at one week-1st follow-up, one month- 2nd follow-up, 6 months 3rd follow-up, and one year final follow-up according to following criteria. 


\section{Clinical evaluation}

\begin{tabular}{|l|l|l|}
\hline Variables & \multicolumn{1}{|c|}{ Success } & \multicolumn{1}{c|}{ Failure } \\
\hline Pain & Absence of pain & $\begin{array}{l}\text { No remission or increase } \\
\text { of pain compare to } \\
\text { preoperative status }\end{array}$ \\
\hline Tendernes & $\begin{array}{l}\text { Absence of tenderness to } \\
\text { percussion }\end{array}$ & $\begin{array}{l}\text { No remission or increase } \\
\text { of tenderness to } \\
\text { percussion compare to } \\
\text { preoperative status }\end{array}$ \\
\hline
\end{tabular}

\section{Result:}

The observations were based on clinical evaluation, the data were tabulated and subjected to statistical analysis by chi-square test or two sided Fisher's ex act test. The results were summarized as follows. Preoperative, post operative clinical findings were recorded.

Table - I

Distribution of samples by affected teeth $(n=60)$

\begin{tabular}{|l|c|c|}
\hline Position of the tooth & Group A & Group B \\
\hline Mandibular first deciduous molar & $2(6.6)$ & $8(26.6)$ \\
\hline Mandibular second deciduous molar & $26(86.6)$ & $18(60.0)$ \\
\hline Maxillary first deciduous molar & $2(6.6)$ & $0(0.0)$ \\
\hline Maxillary second deciduous molar & $0(0.0)$ & $4(13.3)$ \\
\hline Total & $30(100.0)$ & $30(100.0)$ \\
\hline
\end{tabular}

Figure within parentheses indicates in percentage. Group $A=$ Vital tooth (inflamed), Group B= Non vital tooth, $\mathrm{N}=$ Number of patients

To know about the infected tooth of the patient's it was found that highest affected teeth were Mandibular Second deciduous molar 26( 86.6\%) the next Mandibular first deciduous molar 2(6.6), Maxillary first deciduous molar 2 (6.6) and Maxillary second deciduous molar $0(0.0)$ respectively in group- $A$. In group-B highest affected teeth were mandibular second deciduous molar $18(60 \%)$, the next mandibular 1 st deciduous molar $8(26.6 \%)$ and maxillary second deciduous molar $4(13.3 \%)$ respectively.
Table - II

Post-operative pain evaluation $(n=60)$

\begin{tabular}{|c|c|c|c|}
\hline \multicolumn{4}{|c|}{ Groups } \\
\hline Pain (VAS) & Group-A $(n=30)$ & Group $(n=30)$ & $P$ value ${ }^{*}$ \\
\hline \multicolumn{4}{|l|}{ Pre operative } \\
\hline Mild & $18(60 \%)$ & 16 (53.3\%) & $0.999^{\mathrm{NS}}$ \\
\hline Moderate & $12(40 \%)$ & $14(46.7 \%)$ & \\
\hline \multicolumn{4}{|l|}{ 1st follow-up } \\
\hline Absent & $26(86.70 \%)$ & $20(66.7)$ & $0.235^{\mathrm{NS}}$ \\
\hline Mild & $2(6.7 \%)$ & 10 (33.3\%) & \\
\hline - $\quad$ Moderate & $0(0 \%)$ & $0(0 \%)$ & \\
\hline Severe & $2(6.7 \%)$ & $0(0 \%)$ & \\
\hline \multicolumn{4}{|l|}{$2^{\text {nd }}$ follow-up } \\
\hline Absent & $30(100 \%)$ & $30(100 \%)$ & Note done \\
\hline \multicolumn{4}{|l|}{$3^{\text {rd }}$ follow-up } \\
\hline Absent & $30(100 \%)$ & $30(100 \%)$ & Note done \\
\hline Mild & $0(0)$ & $0(0)$ & \\
\hline \multicolumn{4}{|l|}{ Final follow-up } \\
\hline Absent & $30(100 \%)$ & $30(100 \%)$ & Note done \\
\hline
\end{tabular}

* Fisher's exact test was done to measure the level of significance, Figure within parentheses indicates in percentage, Group $A=$ Vital tooth (inflamed), Group $\mathrm{B}=$ Non vital tooth, $\mathrm{N}=$ Number of patients, $\mathrm{NS}=$ Non significant

Table-2:- Shows the post-operative pain evaluation. In group $A$ all patients were presented pre-operative pain (VAS) mild $18(60 \%)$, moderate $12(40 \%)$ and in group-B mild $16(53.3 \%)$, moderate $14(46.7 \%)$ ) cases, 1 st follow-up in group-A, absent, mild, moderate, severe $26(86.7 \%), 2(6.7 \%), 0(0 \%), 2(6.7 \%)$ and in group-B absent, mild, moderate, severe, $20(66.7 \%), 10(33.3 \%), \quad 0(0 \%)$, 2nd follow-up in group-A absent $30(100 \%)$, and in group -B absent $30(100 \%)$, 3rd folloe-up in group-A absent $30(100 \%)$ and in group -B absent $30(100 \%)$ and Final follow-up in group-A absent, $30(100 \%)$ and in group -B absent, $30(100 \%)$ cases respectively. This is statistically non significant. 
Table - III

Post-operative Tenderness to percussion $(n=60)$

\begin{tabular}{|c|c|c|c|}
\hline \multicolumn{4}{|c|}{ Groups } \\
\hline $\begin{array}{l}\text { Tenderness to } \\
\text { percussion }\end{array}$ & \begin{tabular}{|l} 
Group-A \\
$(\mathrm{n}=30)$
\end{tabular} & Group $(n=30)$ & P value* \\
\hline \multicolumn{4}{|l|}{ Pre operative } \\
\hline $\begin{array}{ll}- & \text { Mild } \\
- & \text { Moderat } \\
& \mathrm{e}\end{array}$ & $\begin{array}{c}20(66 \%) \\
0(0 \%)\end{array}$ & $\begin{array}{l}16(53.3 \%) \\
14(46.7 \%)\end{array}$ & $0.710^{\mathrm{NS}}$ \\
\hline \multicolumn{4}{|l|}{$1^{\text {st }}$ follow-up } \\
\hline $\begin{array}{ll}- & \text { Absent } \\
- & \text { Mild } \\
- & \text { Moderat } \\
& \text { e } \\
\end{array}$ & $\begin{array}{l}24(80 \%) \\
4(13.3 \%) \\
2(6.7 \%)\end{array}$ & $\begin{array}{c}16(53.3) \\
14(46.7 \%) \\
0(0 \%)\end{array}$ & $0.148^{\mathrm{NS}}$ \\
\hline \multicolumn{4}{|l|}{$2^{\text {nd }}$ follow-up } \\
\hline Absent & $30(100 \%)$ & $30(100 \%)$ & Not done \\
\hline \multicolumn{4}{|l|}{$3^{\text {rd }}$ follow-up } \\
\hline $\begin{array}{ll} & \text { Absent } \\
- & \text { Mild }\end{array}$ & $\begin{array}{c}30(100 \%) \\
0(0)\end{array}$ & $\begin{array}{c}30(100 \%) \\
0(0 \%)\end{array}$ & $999^{N S}$ \\
\hline \multicolumn{4}{|l|}{ Final follow-up } \\
\hline - $\quad$ Absent & $30(100 \%)$ & $30(100 \%)$ & Note done \\
\hline
\end{tabular}

*Fisher's exact test was done to measure the level of significance, Figure within parentheses indicates in percentage, Group $A=$ Vital tooth, Group B= Non vital tooth, $n=$ Number of patients, NS= Non significant.

Table-3: Shows the post-operative tenderness to percussion. In group-A 20 patients were presented tenderness to percussion mild, 20(66.7\%), and in group- B mild, moderate 16(53.3\%), 14(46.7\%) cases. In 1st follow-up in group- A absent, mild, moderate $24(80.0 \%), 4(13.3 \%), 2(6.7 \%)$ and in group- B absent, mild, moderate 16 (53.3\%), 14(46.7\%), $0(0 \%)$, 2nd follow- up in group- A absent 30(100\%) and in group- B absent $30(100 \%)$, 3rd follow- up in group- A absent, mild 30(100\%), 0(0\%), and in group$\mathrm{B}$ absent, mild $28(93 \%), 2(6.7 \%)$ and final follow- up in group- A absent 30(100\%) and in group- B absent $30(100 \%)$ cases respectively. This is statistically non significant.

\section{Discussion}

Conventional endodontic treatment (pulpectomy) in deciduous molar teeth is very difficult and some times is impracticable due to difficulty in obtaining adequate access to root canals in small mouth, ribbon shaped canal, curve root, presence of permanent tooth bud and physiologic root resorption. Endodontic treatment at the stage of physiologic root resorption is contraindicated by some authorities. ${ }^{11-14}$

Therefore it can be considered that elimination of bacteria from the root canal system by local application of antimicrobial agents as the LSTR 3mix-MP therapy might be an effective and alternative method in endodontic treatment of deciduous teeth. This treatment is simple, no need of mechanical preparation, and does not need long chair time or multiple visit. This treatment is also called as non instrumentation endodontic treatment (NIET).

In the present study 60 patients of their 60 deciduous teeth were successfully treated by LSTR 3Mix-MP therapy. All of the patients were suffering from pain. For further assessment the patient's teeth were divided into two groups: vital inflamed pulp (Initial pulpitis or reversible pulpitis) and non-vital necrosed pulp (with or without periapical lesion). In both groups teeth were treated in same method by using LSTR 3Mix-MP therapy. Finally clinical outcome was evaluated at one week (1st follow-up), one month (2nd follow-up), six months (3rd follow-up) and one year (final follow-up) interval.

In group-A all the cases exhibited pain and 20 cases exhibit mild tenderness to percussion. Carious lesion extends to the pulp. The teeth were response to cold stimuli and electric pulp tester. In group-B all cases presented with pain and tenderness to percussion with large carious lesion and pulpless cavity in which no teeth response to hot or cold stimuli and electric pulp tester. The present study showed that in all cases clinical symptoms such as pain and tenderness to percussion were disappeared in both groups finally. Although four cases in vital group were retreated in the same method at the first follow-up period in which pain and tenderness were increased which may be due to accumulation of inflammatory exudation. After retreatment pain and tenderness gradually disappeared and finally no complications were observed and were considered as success.

In group-A (vital group 22 cases pulp remained vital which were response to stimuli at the end of study. The result is corresponded to the previous study Toyohiko Takushige et al. ${ }^{15}$. So we can call this pulpitis treatment as LSTR 3Mix-MP save pulp therapy, because most inflamed pulps were saved to be alive instead of the removal of pulp tissue in the conventional endodontic therapy.

The result of this prospective clinical study indicate that LSTR therapy using 3 Mix MP mixture of metronidazole, ciprofloxacin and minocyclin (3 Mix) and macrogol and propylene glycol (MP) provided excellent clinical outcomes in prognosis of pain and tenderness in endodontic treatment of deciduous teeth. 


\section{Conclusion:}

The following conclusion was drawn within the limitation of this study. Prognosis of pain and tenderness to percussion in endodontic treatment of deciduous teeth using LSTR 3-Mix MP therapy has shown good clinical success and better in non-vital necrosed pulp when compared with vital inflamed pulp.

\section{References:}

1. Mcdonald RE, Avery DR, Dean JA.Treatment of deep caries, vital pulp exposure, and pulpless teeth. In: McDonald RE, Avery DR, eds. Dentistry for the Child and Adolescent, 8th ed. Philadelphia, Pa: CV Mosby Co: 2004:388412.

2. American academy of pediatric dentistry. Guideline on management of developing dentition and occlusion in pediatric dentistry. Pediatr dent 2012; 34:239-51.

3. Belanger G. Pulp therapy for the primary dentition. Pediatr Dent 1988; 10:257-67.

4. AAPD. Handbook of pediatric dentistry,Casamassimo P,Nowak A. 3rd ed. Edinburg, Scotland: Elsevier;2008.

5. Chougule R, padmanabhan M,mandal M. A comparative evaluation of root canal length measurement techniques in primary teeth. Pediatr Dent2012;34;e53-56.

6. Johnson M, britto L, Guelmann M. Impact of a biological barrier in pulpectomies of primary molars. Pediatr dent 2006; 28:506-10.

7. Sjogren U, Figdor D, persson S, Sundqvist G, Influence of infection at the time of root filling on the outcome of endodontic treatment of teeth with apical periodontitis. Int Endod J 1997; 30:297-306.

8. Takushige T, Cruz E, Moral A, Hoshino E. Endodontic treatment of primary teeth using a combination of antibacterial drugs. Int Endod J 2004; 37:132-8.

9. Hoshino E,Iwaku M. Sato Mi, Ando N, Kota K. Bacterial efficacy of metrodinozole against bacteria of human carious dentin in vivo, Caries Res 1989;23:78-80.

10. Cruz EV, Kota K. Huque J, Iwaku M,Hoshino E:Penetration of propylene glycol through dentine .Int Endod 2002;35:330-36.

11. Belanger GK 1988, Pulp therapy for the primary dentition: In Pinkham JR, ed. Pediatric dentistry Philadelphia. PA, USA:Saunders, pp. 257-67.
12. Koch G, Modeer T, oulsen S, Rasmussen p 1991, pedodontics. Copenhagen. Denmark; Munksgssrd.

13. Camp JH 1994, pediatric endodontic treatment. In:Cohen S, Burns RC, eds. Pathways of the pulp. 6th edn. St Louis, MO, USA: Mosby. pp. 633-71

14. McDonald RE, Avery DR 1994, 'Dentistry for the child and Adolescent. 6th edn. St Louis,USA; Mosby.

15. Toyohiko Takushige, Edward Venzon, Md. Ali Asgor Moral, Non-surgical treatmzent of pulpitis, including those with history of spontaneous pain, using a combination of antibacterial drugs. Int LSTR therapy Vol 7: 1-5. 2008 